\title{
Prediction of late normal tissue complications in RT treated gynaecological cancer patients: Potential of the $\gamma$-H2AX foci assay and association with chromosomal radiosensitivity
}

\author{
JOKE WERBROUCK ${ }^{1}$, KIM DE RUYCK ${ }^{1}$, LAURENCE BEELS ${ }^{1}$, ANNE VRAL ${ }^{1}$, \\ MARC VAN EIJKEREN ${ }^{2}$, WILFRIED DE NEVE ${ }^{2}$ and HUBERT THIERENS ${ }^{1}$ \\ ${ }^{1}$ Department of Basic Medical Sciences, Ghent University; ${ }^{2}$ Department of \\ Radiation Oncology, Ghent University Hospital, Ghent, Belgium
}

Received September 14, 2009; Accepted October 27, 2009

DOI: 10.3892/or_00000671

\begin{abstract}
In the present study, the $\gamma-\mathrm{H} 2 \mathrm{AX}$ assay was investigated as a predictive test for the development of late normal tissue complications. Therefore, phosphorylated histone H2AX $(\gamma-\mathrm{H} 2 \mathrm{AX})$ foci were scored in peripheral blood T-lymphocytes of gynaecological radiotherapy patients, irradiated in vitro with a high dose rate (HDR) and a low dose rate (LDR) protocol. The $\mathrm{G}_{2}$ chromatid break assay was used to compare chromosomal radiation sensitivity with DNA doublestrand-break (DSB) repair capacity. Late normal tissue reactions were scored according to the Common Terminology Criteria for Adverse Events (CTCAE) version 3.0 scale. In our analyses, no differences in foci kinetics were found between the non to mild and moderate to severe patient groups after HDR irradiation. Furthermore, no relation was observed between the level of residual $\gamma-\mathrm{H} 2 \mathrm{AX}$ foci and CTC score after LDR irradiation. On the contrary, the number of chromatid breaks was associated with late clinical radiation sensitivity. Comparison of $\mathrm{G}_{2}$ chromatid break assay data with the residual number of radiationinduced foci after LDR irradiation and repair times after HDR irradiation showed no relationship between the assays. From this study we can conclude that scoring of $\gamma$-H2AX foci after in vitro irradiation of isolated T-lymphocytes of patients is not predictive for late radiotoxicity. This applies as well to the assessment of the repair kinetics after an HDR dose as to the determination of the number of residual foci after a LDR dose.
\end{abstract}

Correspondence to: Dr Joke Werbrouck, Department of Basic Medical Sciences, Ghent University, Proeftuinstraat 86, B-9000 Ghent, Belgium

E-mail: joke.werbrouck@ugent.be

Key words: gynaecological cancer, $\gamma-\mathrm{H} 2 \mathrm{AX}$ foci, late normal tissue complications, DNA DSB repair, radiosensitivity assay

\section{Introduction}

Radiation therapy is an important treatment modality in the management of gynaecological cancer (1). The final goal of the therapy is to deliver a total dose to the tumour that eliminates the cancer cells. The total tumour dose is, however, restricted to the tolerance dose of the surrounding normal tissues present in the treatment volume (2). The cervix and corpus uteri tolerate very high radiation doses. The limiting factor lies in the dose to the tissues of the sigmoid colon and the rectum which are sensitive to radiation injury (3). Using contemporary fractionation schemes for irradiation of the pelvic region, the accepted risk of severe late complications is less than $5 \%$ (1). Nevertheless, a large patient-to-patient variety in incidence and severity of normal tissue complications is seen in the clinic, even in cases where patients were treated with nearly identical irradiation schemes (4). For about one third of the irradiated cancer patients, differences in dose volume metrics (e.g., tumour dose, fractionation scheme), additional treatment modalities (chemotherapy, surgery) and patient specific factors (e.g., age, gender, comorbidities) are the main contributors to the development of adverse reactions. For the majority of the cases, variation in intrinsic genetic determinants are responsible for the normal tissue toxicities (5).

The hypersensitivity to ionizing radiation, seen in patients carrying germline mutations in genes responsible for DNA DSB repair and/or detection (ataxia telangiectasia, ATM; LigaseIV deficiency, LigIV), were the first suggestions for an inherited genetic basis for radiation sensitivity. However, the extreme sensitivity to ionizing radiation due to these penetrant mutations, are not representative for the general population. Clinical radiation sensitivity can develop as a result of a combined effect of small variations in multiple genes functioning in those specific DNA DSB repair pathways (6).

A number of assays have been proposed in the past to determine the intrinsic radiation sensitivity of patients. The ultimate goal is to develop an in vitro predictive test to detect differences in radiation sensitivity among patients and as a result, increasing complication-free cure rates due to an adaptation of the radiation therapy scheme to the intrinsic 
radiation sensitivity of the patient. Fibroblasts and, especially, peripheral blood lymphocytes are easily obtained from a patient without any additional harmful procedures. The nucleus of fibroblasts and lymphocytes contains the same genetic information as the cells present in the irradiated normal tissues. Therefore, they should exhibit the same reaction to ionizing radiation. Clonogenic survival tests on fibroblasts need long culture times and had variable success in the prediction of a patient's radiation sensitivity (7). The reliability of cytogenetic assays, using other biological endpoints such as chromosomal damage (dicentrics, micronucleus) and chromatid breaks $\left(\mathrm{G}_{2}\right.$ assay) was not sufficient to be applied in clinical practice (8-10). Amongst the tests developed to investigate DNA damage (e.g. comet assay and PFGE), the comet assay has the most potential as a predictor assay for clinical radiation sensitivity, but again, sensitivity and specificity were too low to use the test in daily radiation therapy practice (2,11-13). Genetic tests concerning subtle variations in DNA DSB repair genes, as single nucleotide polymorphisms, have shown to be associated with radiation injury after radiation therapy (14-16).

A decade ago, a promising new technique was developed by Rogakou et al (17) for detection of DNA DSB: the $\gamma$ $\mathrm{H} 2 \mathrm{AX}$ assay. The H2AX protein represents one of the three subfamilies of the H2A family of histone proteins (18). The $\mathrm{H} 2 \mathrm{~A}$ family contains specific $\mathrm{NH}_{2-}$ and $\mathrm{COOH}$-tail specific sequences that strongly have been conserved throughout evolution and are targets for post-translational modifications (17). The H2AX protein isoform contains a specific C-terminal $\mathrm{SQ}(\mathrm{D} / \mathrm{E})(\mathrm{I} / \mathrm{L} / \mathrm{Y})$ tail motif which is a consensus Ser phosphorylation site for the PI-3 kinase family, mainly ATM after radiation-induced damage. This Ser139 residue becomes phosphorylated within 1-3 min after exposure to ionizing radiation and is one of the earliest cellular responses to DNA DSB induction $(18,19)$.

It has been shown that the $\gamma-\mathrm{H} 2 \mathrm{AX}$ proteins are docking sites for thousands of repair and checkpoint proteins and these foci are responsible for retention of the repair and checkpoint proteins near the DNA DSB (20). Bassing et al (21) demonstrated that mouse embryonic stem cells, deficient for both of the $\mathrm{H} 2 \mathrm{AX}$ alleles, are highly radiosensitive. Moreover, a significant increase in chromosomal abnormalities was demonstrated. Furthermore, studies in Saccharomyces cerevisiae indicates that phosphorylation of the Ser139 residue facilitates DNA DSB repair by the Non-Homologous End Joining pathway, the major DNA DSB repair mechanism in mammalian cells $(18,22)$. The strength of the $\gamma$-H2AX assay is that one $\gamma-\mathrm{H} 2 \mathrm{AX}$ focus correlates with one DNA DSB (19).

Differences in the repair kinetics of DNA DSBs are possibly related to differences in radiation sensitivity among individuals. A more rapid loss of $\gamma-\mathrm{H} 2 \mathrm{AX}$ foci in human cell lines has been correlated with higher survival rates, which could indicate a better repair of DNA DSB and higher resistance to ionizing radiation (23). This leads to the hypothesis that correct processing of the DNA DSB could be associated with the kinetics of $\gamma-\mathrm{H} 2 \mathrm{AX}$ foci.

In the present study, the possibility of the use of the $\gamma$ $\mathrm{H} 2 \mathrm{AX}$ foci assay as a predictive marker for the development of late normal tissue complications was examined.
Table I. Distribution of treatment protocols for the CTC0-1 and CTC2+ patient groups.

\begin{tabular}{lcc}
\hline $\begin{array}{l}\text { Treatment } \\
\text { protocol }\end{array}$ & $\begin{array}{c}\text { CTC0-1 } \\
\mathrm{n}(\%)\end{array}$ & $\begin{array}{c}\text { CTC2+ } \\
\mathrm{n}(\%)\end{array}$ \\
\hline $\begin{array}{l}\text { Radiation therapy } \\
\text { Chemoradiotherapy }\end{array}$ & $1(5.6)$ & $1 \quad(9.1)$ \\
$\begin{array}{l}\text { Radiation therapy } \\
\text { and surgery }\end{array}$ & $12(11.0)$ & $0 \quad(0.0)$ \\
$\begin{array}{l}\text { Chemoradiotherapy } \\
\text { and surgery }\end{array}$ & $3(16.7)$ & $3(27.3)$ \\
\hline
\end{tabular}

Experiments were performed on peripheral blood Tlymphocytes for a group of gynaecological radiation therapy patients. Two patient groups composed of non to mild (CTC0-1) and moderate to severe (CTC2+) responders were compared for possible differences in repair kinetics after an acute in vitro 0.5 Gy HDR irradiation of isolated T-lymphocytes. This comparison was also performed for differences in number of persistent foci after an overnight LDR irradiation of $2.2 \mathrm{~Gy}$. In addition, the correlation between the results of the $\mathrm{G}_{2}$ radiation sensitivity assay, obtained predominantly in a previous study, and the $\gamma-\mathrm{H} 2 \mathrm{AX}$ foci data after HDR and LDR irradiation, was investigated.

\section{Materials and methods}

Study subjects. The study population consisted of 29 female patients treated for cervix cancer $(n=12)$ or endometrial cancer $(n=17)$ at the Ghent University Hospital between January 1999 and April 2005. These patients represent a subgroup of patients of a previous study, supplemented with 5 additional patients (8). In brief, all patients received fractionated external beam radiation therapy to the pelvis. Administered tumour doses ranged from 45 to $50 \mathrm{~Gy}$ (fractions 1.8-2.0 Gy/fraction). One patient received $45 \mathrm{~Gy}$ and a $10-\mathrm{Gy}$ boost ( $2 \mathrm{~Gy} /$ fraction). Except for 1 patient, the external beam radiation therapy was followed by a brachytherapy boost, with doses ranging from 15 to $34 \mathrm{~Gy}$. Nineteen patients received radiation therapy combined with surgical intervention, 2 patients underwent combined chemoradiotherapy, 6 patients received chemoradiotherapy in combination with surgical intervention and 2 patients received only radiation therapy. The distribution of treatment protocols for the CTC0-1 and CTC2+ patient groups are shown in Table I. The median age of the patients at the moment of treatment was 61 years (range, 32-77).

Clinical radiation sensitivity was determined using the CTCAE scale, version 3.0, of the National Cancer Institute based on observable late normal tissue reactions (24). Of the 29 patients, 18 showed no or very mild reactions and were classified as CTC0-1 responders. Six patient showed moderate reactions (CTC2; radiation enteritis with diarrhea, blood in stool and haemorrhoidal suffering; osteoradionecrosis; intermittent radiocystitis, radiation rectitis and vaginitis; miction problems with pollakisuria and urine incontinence; mild 
vaginal atrophy with telangiectases and pelvic fibrosis), 3 patients had serious side effects resulting from the radiation therapy (CTC3; radiation enteritis with anal blood loss and ulceration, vaginal atrophy and vaginal fibrosis) and 2 patients suffered from life-threatening complications (CTC4; radiation enteritis with pelvic fibrosis, vaginal atrophy with synechia and telangiectases, blood loss, rectal ulcers resulting in bowel resection). The median follow-up period was 6.2 years (2.9-12.4 years).

Blood samples were collected during the annual medical examination. The collection of the patient blood samples was started in October 2007. Blood samples were collected in two 10-ml heparinised tubes. Written informed consent was obtained of each of the participating individuals. Healthy donors included in present study are volunteers working in the Basic Medical Science Department. This study was approved by the Ethics Committee of the Ghent University Hospital.

T-lymphocyte isolation. Peripheral blood lymphocytes are a mixture of different subtypes of cells, B- and T-lymphocytes. To avoid any confounding through the use of different subsets of cells, T-lymphocytes were separated from the lymphocyte pool by means of the RosetteSep Human T cell Enrichment Cocktail (StemCell, Grenoble, France). Briefly, after incubation with the RosetteSep cocktail, whole blood was diluted with phosphate-buffered saline (PBS) (Sigma-Aldrich, Bornem, Belgium) containing 2\% of Foetal Calf Serum (FCS) (Life Technologies, Merelbeke, Belgium). The diluted blood was layered onto RosetteSep DM-L density medium and centrifuged. The T-lymphocytes are present as a highly enriched population at the interphase between the plasma and the density medium. These T-lymphocytes are washed twice with PBS (2\% FCS) and resuspended in RPMI-1640 culture medium supplemented with FCS, L-glutamine, $50 \mathrm{U} /$ $\mathrm{ml}$ penicillin and $50 \mu \mathrm{g} / \mathrm{ml}$ streptomycin. Cells were incubated in a humidified $5 \% \mathrm{CO}_{2}$ atmosphere at $37^{\circ} \mathrm{C}$ (Thermo Scientific, Erembodegem, Belgium). The separation resulted in a pure T-lymphocyte population with a B-lymphocyte contamination of $<0.2 \%$ (flow cytometry analysis).

Irradiation protocol. In vitro $\gamma$-irradiation was performed in a water bath at $37^{\circ} \mathrm{C}$ with ${ }^{60} \mathrm{Co}$ rays. Aliquots were distributed over a total of 7 falcon tubes. One of them served as a control sample and one was irradiated overnight at LDR (14.7 cGy/h), to a total dose of $2.2 \mathrm{~Gy}$. The remaining falcon tubes were irradiated the following day with $0.5 \mathrm{~Gy}$ at $\operatorname{HDR}(0.5 \mathrm{~Gy} / \mathrm{min})$. In this HDR experiment, T-lymphocytes were allowed to repair the induced DNA damage during different time intervals after irradiation ( $30 \mathrm{~min}, 1,3,5$ and $24 \mathrm{~h}$ ) at $37^{\circ} \mathrm{C}$, to accurately assess the rate of loss of $\gamma$-H2AX foci. Thirty minutes post-irradiation was the first time-point to determine the initial radiation-induced DNA DSBs. To stop the ongoing repair processes, the cell suspensions were put in ice water.

Immunohistochemistry. After the appropriate repair times, $0.5 \mathrm{ml}$ of the cell suspension was centrifuged onto poly-Llysine coated slides using a cytospin centrifuge (SigmaAldrich). Cells were fixed in 3\% paraformaldehyde (PFA) (Sigma-Aldrich) in phosphate-buffered saline (PBS). Subse- quently cells were rinsed in PBS and permeabilized on ice with $0.2 \%$ Triton X-100 (Sigma-Aldrich). Cells were washed in PBS [1\% bovine serum albumin (BSA)] (Roche, Mannheim, Germany) and then stained with primary mouse monoclonal anti- $\gamma$-H2AX antibody (1:300) (Biolegend, Antwerpen, Belgium). After washing in PBS (1\% BSA), cells were exposed to the second polyclonal rabbit anti-mouse antibody conjugated with tetramethyl rhodamine isothiocyanate (TRITC) (1:1000) (DakoCytomation, Glostrup, Denmark). After rinsing in PBS, cells were mounted in slow-fade mounting medium containing 2\% 4',6-diamino-2-phenylindole (DAPI) (Sigma-Aldrich) to counterstain the nucleus beneath a coverslip.

Foci analysis. Images were viewed using Cytovision v.2.8 Software 2002 (Applied Imaging, CA, USA) and captured using a digital camera (Applied Imaging). Images were acquired using an Olympus BX60 fluorescent microscope equipped with a 100x/1.30 oil lens. The TRITC signal was acquired from optical sections with a spacing of $1.03 \mu \mathrm{m}$ in the Z-axis (Z-stack). Ten optical sections were obtained for each field of vision. For the DAPI staining, no focal planes were used. The final image was obtained by the projection of all sections in one plane, combined with the DAPI staining. The foci were scored on these final images on screen. In each experiment, 150-250 cells from 15-25 randomly selected fields of vision were analyzed.

$G_{2}$ chromatid break assay. The $\mathrm{G}_{2}$ data for most patients were adopted from a previous study (8). For 5 additional patients, the $\mathrm{G}_{2}$ assay (Paterson Institute, Manchester, UK) was performed as described previously (8).

Statistical analysis. Statistical analyses were performed using Microsoft office Excel 2003 and Statistical Package for Social Sciences (SPSS), version 15.0, software. The MannWhitney $\mathrm{U}$ test was used to evaluate if significant differences were present between the CTC0-1 and CTC2+ groups. Distribution of therapy and patient related factors of radiosensitive patients and non-radiosensitive patients were compared using the $\chi^{2}$ test. P-values of $<0.05$ were considered as statistically significant.

\section{Results}

Influence of therapy related factors on the development of adverse effects. Late normal tissue complications in the pelvic region were considered as clinical end-points in the present study. To avoid variation in interpretation of the clinical reactions, the scoring of the late averse effects was performed by the same radiation oncologist for each patient. Most of the patients included in this study received additional treatments like chemotherapy and surgical intervention. These varying treatment modalities can have profound influence on the development of severe toxicities independent from the intrinsic differences in DNA DSB repair capacity between the patients. The distribution of the patients receiving chemotherapy or surgery did not significantly differ between the CTC0-1 and CTC2+ patient groups ( $\mathrm{p}=0.985$ and 0.690 , respectively). Moreover, moderate to severe responding 


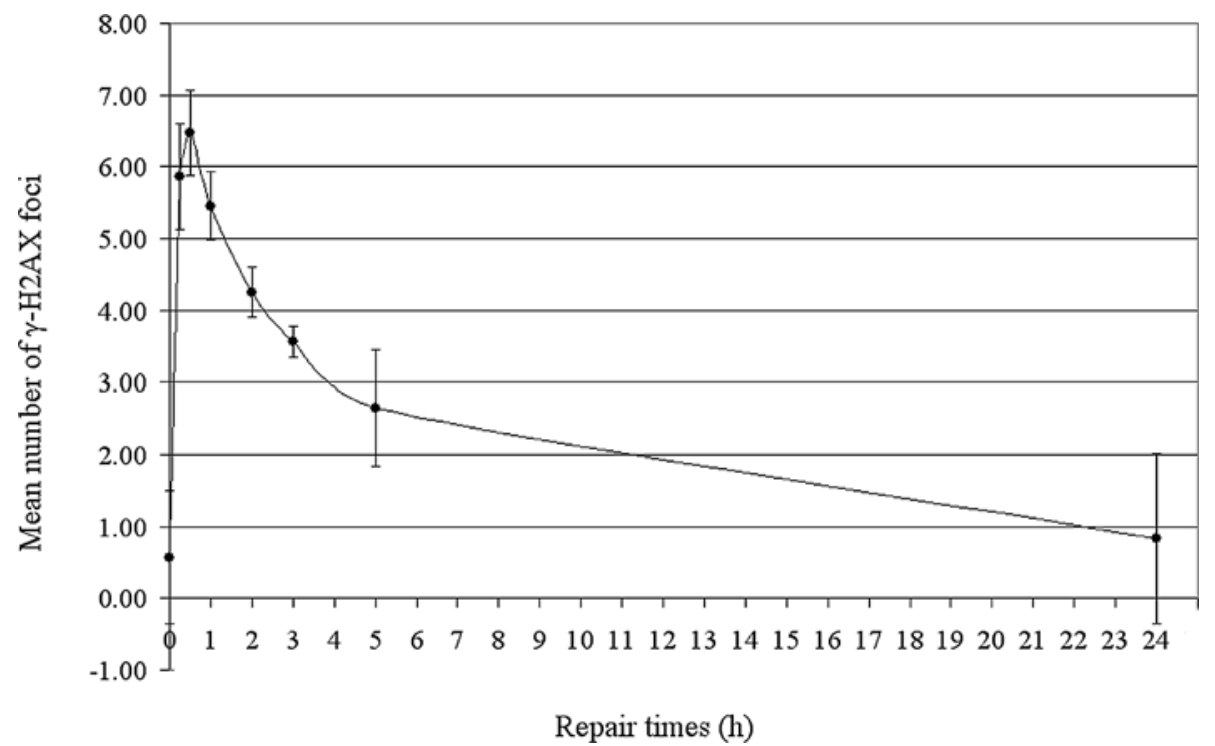

Figure 1. Repair kinetics after an acute HDR dose of 0.5 Gy. Repair curve averaged over 3 healthy donors. Error bars represent the standard deviation based on inter-individual variation of 3 healthy donors.

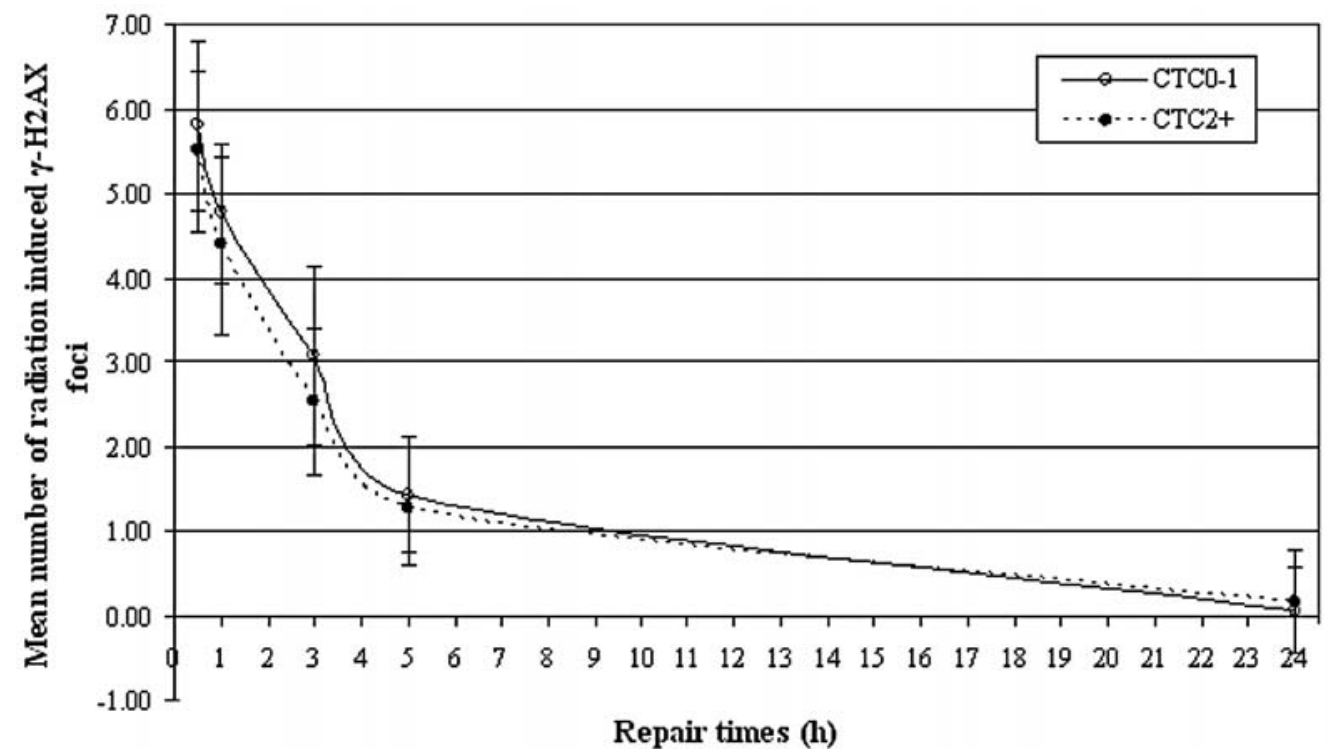

Figure 2. Comparison of the kinetics of the radiation-induced $\gamma-\mathrm{H} 2 \mathrm{AX}$ foci between the group of gynaecological patients with non to mild late reactions (CTC0-1) and moderate to severe reactions (CTC2+) after an acute 0.5 Gy HDR dose. Error bars represent the standard deviation based on the inter-individual variability of 18 (CTC0-1) and $11(\mathrm{CTC} 2+)$ individuals.

patients did not receive significantly higher total tumour doses of external radiation compared to the non to mild responding patients (mean=47.7 and 46.9, respectively; $p=0.131$ ). Furthermore, the administered radiation dose with brachytherapy did not influence CTC classification between the non to mild and moderate to severe reaction patient groups (mean=19.5 and 20.4, respectively; $\mathrm{p}=0.588$ ).

Optimization of the $\gamma-H 2 A X$ assay as radiation sensitivity assay. Preceding the study on patient material, the $\gamma-\mathrm{H} 2 \mathrm{AX}$ assay was optimized as a radiation sensitivity assay using protocols based on in vitro HDR and LDR irradiation of Tlymphocytes.
For the HDR protocol, the time course of formation and disappearance of the $\gamma$-H2AX foci after an acute HDR ${ }^{60} \mathrm{Co}$ $\gamma$-irradiation was measured. Doses of 0.5 and $1.0 \mathrm{~Gy}$ are frequently used in DNA repair studies using $\gamma-\mathrm{H} 2 \mathrm{AX}$ foci. After a dose of $1 \mathrm{~Gy}$, the number of foci was high and, according to us, no reliable quantification of the induced foci could be performed due to overlap of the spots. In our hands, a dose of $0.5 \mathrm{~Gy}$ is optimal in radiation sensitivity studies in view of the statistics and avoidance of foci overlap. Fig. 1 shows the repair kinetics averaged over 3 healthy donors after an acute dose of $0.5 \mathrm{~Gy}$. A clear drop of the foci with increasing repair times can be noted. Foci formation is continuing between 15 and $30 \mathrm{~min}$ after irradiation and 


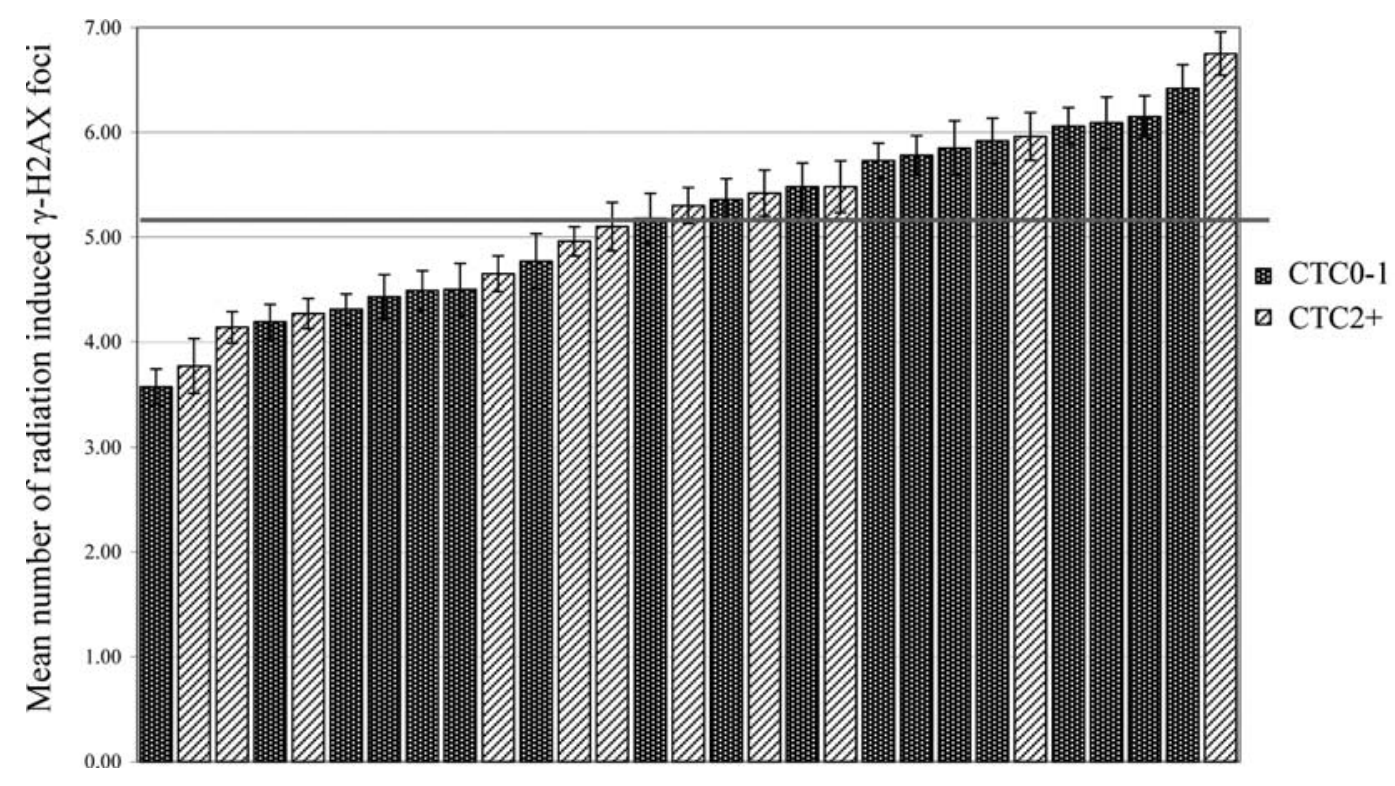

Figure 3. Ranking of the patients according to their radiation-induced $\gamma$-H2AX foci after an overnight LDR irradiation with a cumulative dose of 2.2 Gy $(14.7 \mathrm{cGy} / \mathrm{h})$. The dark bars represent the patients with non to mild late radiotoxic effects $(\mathrm{CTC} 0-1)$, the hatched bars represent the patients with moderate to severe late radiotoxic effects (CTC2+). The horizontal line represents the mean number of $\gamma-\mathrm{H} 2 \mathrm{AX}$ foci of the total patient group ( $\mathrm{n}=5.18)$. The error bars represent the standard error of the mean (SEM).

reaches a maximum after $30 \mathrm{~min}$. The half life of the foci is about $3 \mathrm{~h}$.

For the LDR protocol, the residual number of $\gamma-\mathrm{H} 2 \mathrm{AX}$ foci after an overnight irradiation was evaluated. Our irradiation protocol was based on the one used by Kato et al (25) for the examination of DNA DSB repair efficiency in cell strains derived from patients carrying one or both germline mutations in the ATM gene. We reduced the $24 \mathrm{~h}$ irradiation time to an overnight irradiation with a cumulative dose of 2.2 Gy (14.7 cGy/h).

Association between late clinical radiation sensitivity and in vitro induced $\gamma-H 2 A X$ foci in gynaecological patients treated with radiation therapy. The patients were subdivided according to their CTC score for late normal tissue radiotoxicity. The HDR protocol was applied to the radiation therapy treated gynaecological patient group and the CTC0-1 and $\mathrm{CTC} 2+$ groups were compared for possible differences in DNA DSB repair kinetics. No differences were found in the number of background foci (0.92 and 0.84 for CTC $0-1$ and CTC2+ respectively; $\mathrm{p}=0.637$ ). For both groups, the curves representing the time-dependence of ionizing radiationinduced $\gamma$-H2AX foci (background excluded) are in close proximity (Fig. 2). Moreover, $24 \mathrm{~h}$ after IR exposure, no excess of foci was seen for the CTC $0-1$ as well for the CTC2+ group (0.06 and 0.16 respectively; $\mathrm{p}=0.594)$.

Using the LDR protocol, the CTC $0-1$ and $\mathrm{CTC} 2+$ patients were compared for their mean number of ionizing radiationinduced $\gamma$-H2AX foci after LDR irradiation (background excluded) (Fig. 3). The mean number of foci for the CTC0-1 and CTC2+ groups was 5.24 and 5.07, respectively. The figure shows very clearly that no significant relationship exists between toxicity score and foci number after LDR irradiation ( $\mathrm{p}=0.458)$.

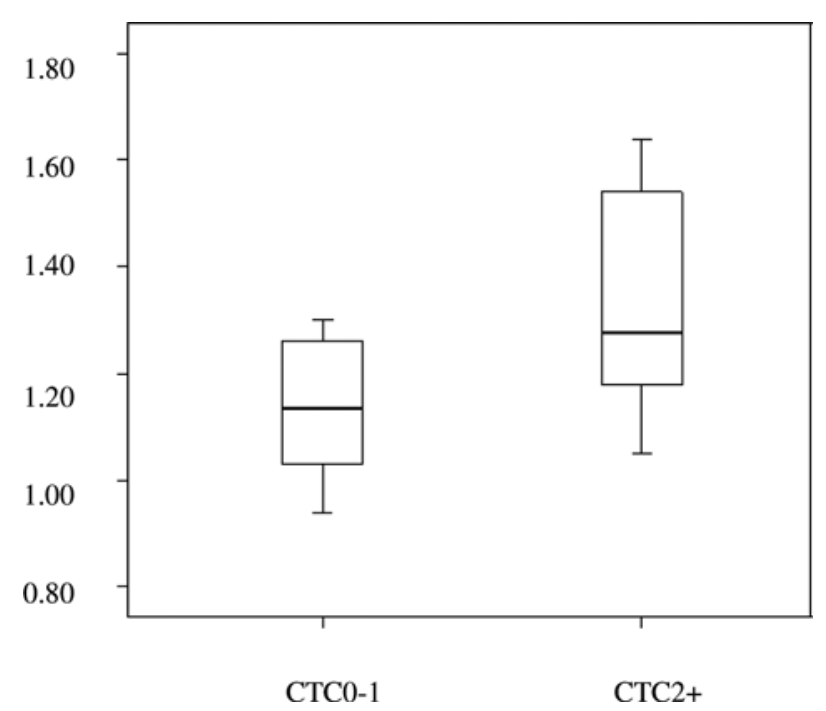

Figure 4. Boxplots representing the correlation between the $\mathrm{G}_{2}$ score and the CTC score for late adverse events.

$\gamma$-H2AX foci and $G_{2}$ chromatid break assay. The association between $\mathrm{G}_{2}$ assay and clinical radiation sensitivity in the radiation therapy patient population under study has been demonstrated previously (8). For the subgroup of patients used in the present study, the average number of chromatid breaks $\left(\mathrm{G}_{2}\right.$ score $)$ per cell for patients in the CTC2+ group was significantly higher compared to the CTC 0 - 1 group (1.32 and 1.14 , respectively; $p=0.044)$. Fig. 4 shows the distribution of the chromatid breaks per cell for the CTC0-1 and CTC2+ groups. The patients of this subpopulation show a similar distribution in number of chromatid breaks per cell as was 


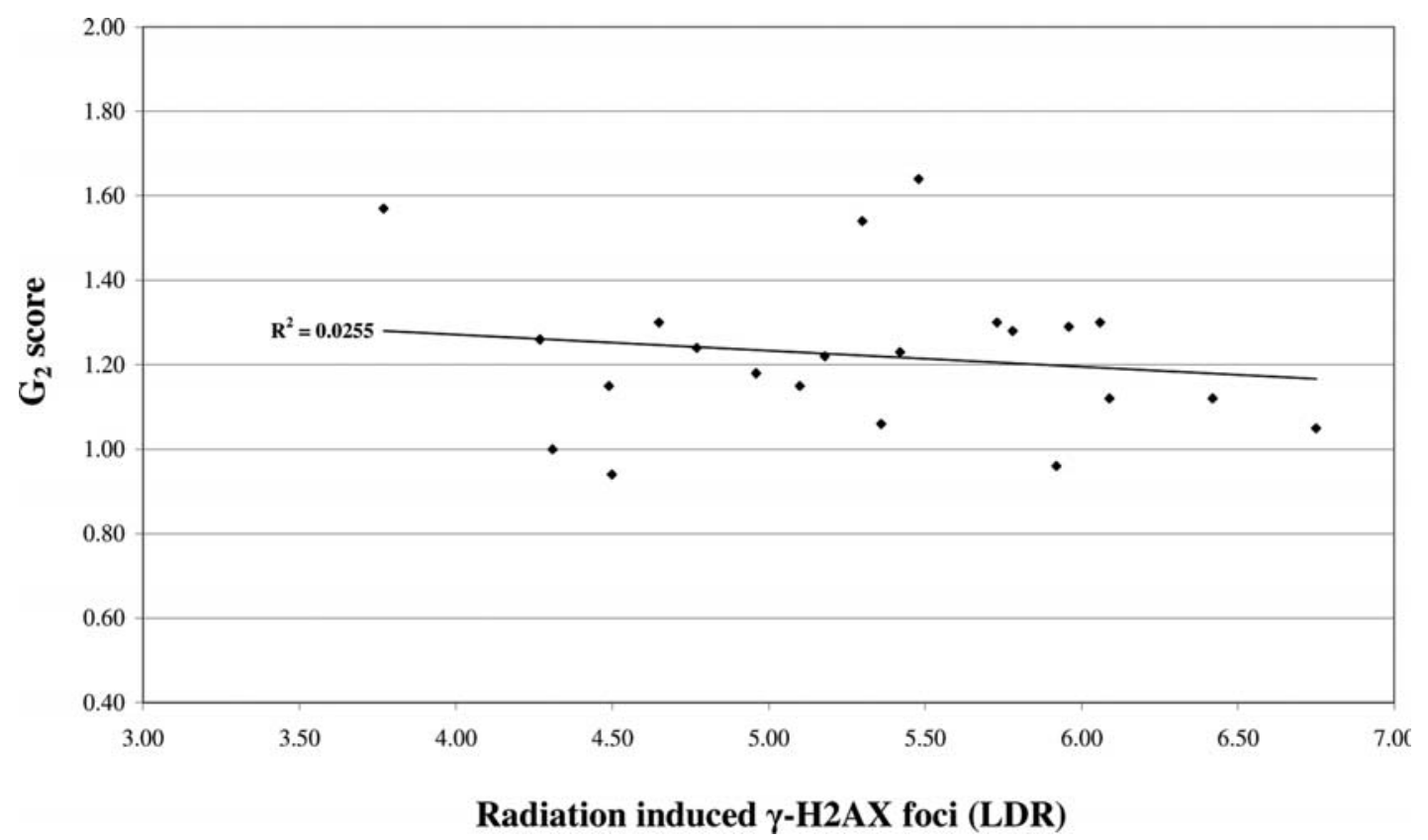

Figure 5. Correlation between the $\mathrm{G}_{2}$ score and the mean number of persistent radiation-induced $\gamma-\mathrm{H} 2 \mathrm{AX}$ foci after LDR irradiation for the complete gynaecological patient group.

seen in the original, larger study population (8). In the present study, the correlation between the $\mathrm{G}_{2}$ score and i) the mean number of foci after 2.2 Gy LDR irradiation (background exclusive) and ii) the mean number of foci $30 \mathrm{~min}, 1,3,5$ and $24 \mathrm{~h}$ after a 0.5 Gy HDR dose (background exclusive) was examined. For the present group of patients, no correlation was found between the $\mathrm{G}_{2}$ score and the number of radiation-induced $\gamma-\mathrm{H} 2 \mathrm{AX}$ foci after HDR irradiation for the complete group as well as for the 2 subgroups separately $(\leq 0.177 \mathrm{p} \leq 0.954)$. Furthermore, no association could be demonstrated between the G2 assay and the residual number of radiation-induced $\gamma$-H2AX foci after an overnight LDR irradiation ( $\mathrm{p}=0.478$ ) (Fig. 5). The same conclusion holds also for the CTC0-1 and CTC2+ patient groups separately $(\mathrm{p}=0.312$ and 0.258 , respectively).

\section{Discussion}

Together with the improvement of the radiation therapy techniques, the need for a sensitive and fast predictive test for the identification of patients at higher risk for the development of severe normal tissue complications, is gaining attention. The accessibility of such an assay could lead to an improvement of treatment planning and a minimisation of the toxicities resulting from the cancer treatment. In the past decades, several cellular and cytogenetic assays have been developed to this aim. Although some of these assays showed encouraging results with clear associations with specific normal tissue complications, acute as well as late, a sensitive assay which allows prediction at the individual patient level is not yet available $(8,10,26,27)$.

An exciting new technique is the $\gamma-\mathrm{H} 2 \mathrm{AX}$ foci assay, in which each focus corresponds to one DNA DSB in the cell nucleus. It has been demonstrated that cell strains exhibiting a radiosensitive phenotype, derived from tumours as well as normal tissues, retain $\gamma-\mathrm{H} 2 \mathrm{AX}$ foci for a longer period of time compared to radioresistant cell strains. This could indicate a lower capacity to repair the induced DNA DSBs $(14,23,28-31)$. The fraction of the foci remaining $24 \mathrm{~h}$ after exposure was shown to be correlated with the clonogenic survival fraction after a dose of 2 Gy (29). Because radiation sensitivity and cell survival both have been associated in literature with longer retention of the $\gamma$-H2AX foci, we hypothesized that radiation therapy patients showing severe sensitivity to ionizing radiation will show a slow rate of disappearance of the $\gamma$-H2AX foci. As a result, measurement of the repair kinetics of DNA DSB by scoring the $\gamma-\mathrm{H} 2 \mathrm{AX}$ foci is a good candidate for cellular radiosensitivity marker. Kinetics of disappearance of the $\gamma$-H2AX foci in lymphocytes is representative for DNA DSB repair in other tissues. This has been demonstrated by means of mouse strains carrying subtle polymorphisms or mutations in genes involved in DNA DSB repair (32).

The differences in response to ionizing radiation in clinical practice are not that extreme as is seen for radiosensitive cell strains or cells derived from individuals suffering from radiation sensitivity syndromes. Therefore, small impairments in DNA DSB repair capacity could be enlarged using protracted LDR irradiation. Therefore, $\gamma-\mathrm{H} 2 \mathrm{AX}$ foci were also scored after overnight in vitro LDR irradiation.

Comparing $\gamma$-H2AX foci kinetics between gynaecological cancer patients with moderate to severe late reactions (CTC2+) and non to mild reactions (CTC0-1) after radiation therapy showed no differences between both groups. The ranking of the patients according to the number of radiation-induced $\gamma$ H2AX foci after LDR irradiation was not correlated at all with clinical radiation sensitivity. So, the $\gamma$-H2AX technique applied in the present study, could not differentiate between gynaecological radiation therapy patients with different grades of normal tissue complications using in vitro irradiated $\mathrm{T}$ lymphocytes. Because no differences in treatment related 
factors could be demonstrated between our patient groups, these factors can not be responsible for the lack of correlation in this patient subset. Therefore, although a relatively small number of patients was included in the present study, the study design was appropriate to give an indication of the capacity of the $\gamma$-H2AX assay in the prediction of normal tissue radiation sensitivity. An explanation for the lack of correlation can be found in the aetiology of late normal tissue reactions. Fibrotic and inflammatory processes play an important role in the induction of late adverse effects in addition to DNA repair mechanisms immediately after the induction of a DNA DSB. Olive et al (33) also failed to demonstrate a relationship between the foci data and late clinical radiation sensitivity.

Previously, an association was reported between chromosomal damage assessed by the $\mathrm{G}_{2}$ assay and clinical radiation sensitivity using the radiation therapy patient group under study. However, the $\mathrm{G}_{2}$ assay could not be used as a predictive assay on an individual basis for the gynaecological patients (8). In the present study the association between the $\mathrm{G}_{2}$ score and clinical radiation sensitivity remained. A comparison was made between the number of radiation-induced chromatid breaks on the one hand, and the number of radiationinduced foci after an LDR and HDR dose on the other hand. The data did not show any correlation between the endpoints. An explanation for this lies in the fact that the $\mathrm{G}_{2}$ score not only measures the efficiency of a person's DNA repair capacity but also reflects differences in $\mathrm{G}_{2}$ cell cycle checkpoint delay. Moreover, during the $\mathrm{G}_{2}$ assay, T-lymphocytes are stimulated to divide, while for the $\gamma-\mathrm{H} 2 \mathrm{AX}$ protocol non-dividing T-lymphocytes were used. The absence of a correlation between the foci data and the $\mathrm{G}_{2}$ score could also be due to a different repair pattern between dividing and nondividing T-lymphocytes.

\section{Acknowledgements}

The study was supported by a grant of the Bijzonder Onderzoeksfonds (Ghent University, No. 01D30006). We wish to thank all the patients who participated in this study. We are also grateful to the nursing staff of the department of Radiation Oncology at the Ghent University Hospital for the collection of the patient blood samples.

\section{References}

1. Ahamad A and Jhingran A: New radiation techniques in gynecological cancer. Int J Gynecol Cancer 14: 569-579, 2004.

2. Gabelova A, Farkasova T, Gurska S, Machackova Z, Lukacko P and Witkovsky V: Radiosensitivity of peripheral blood lymphocytes from healthy donors and cervical cancer patients; the correspondence of in vitro data with the clinical outcome. Neoplasma 55: 182-191, 2008.

3. Tewari KS and DiSaia PJ: Radiation therapy for gynecologic cancer. J Obstet Gynaecol Res 28: 123-140, 2002.

4. Tucker SL, Geara FB, Peters LJ and Brock WA: How much could the radiotherapy dose be altered for individual patients based on a predictive assay of normal tissue radiosensitivity? Radiother Oncol 38: 103-113, 1996.

5. Andreassen CN, Alsner J and Overgaard J: Does variability in normal tissue reactions after radiotherapy have a genetic basis where and how to look for it. Radiother Oncol 64: 131-140, 2002.
6. Andreassen $\mathrm{CN}$ : Can risk of radiotherapy-induced normal tissue complications be predicted from genetic profiles? Acta Oncol 44: 801-815, 2005.

7. Peacock J, Ashton A, Bliss J, et al: Cellular radiosensitivity and complication risk after curative radiotherapy. Radiother Oncol 55: 173-178, 2000.

8. De Ruyck K, van Eijkeren M, Claes K, et al: Radiation-induced damage to normal tissues after radiotherapy in patients treated for gynecologic tumors: association with single nucleotide polymorphisms in $X R C C 1, X R C C 3$ and $O G G 1$ genes and in vitro chromosomal radiosensitivity in lymphocytes. Int $\mathrm{J}$ Radiat Oncol Biol Phys 62: 1140-1149, 2005.

9. Willems P, Claes K, Baeyens A, et al: Polymorphisms in nonhomologous end joining genes associated with breast cancer risk and chromosomal radiosensitivity. Genes Chromosomes Cancer 47: 137-148, 2008.

10. Barber JBP, Burrill W, Spreadborough AR, et al: Relationship between in vitro chromosomal radiosensitivity of peripheral blood lymphocytes and the expression of normal tissue damage following radiotherapy for breast cancer. Radiother Oncol 55: 179-186, 2000.

11. Bourguignon MH, Gisone PA, Perez MR, Michelins S, Dubner D, Giorgio MD and Carosella ED: Genetic and epigenetic features in radiation sensitivity. Part II: Implications for clinical practice and radiation protection. Eur J Nucl Med Mol Imaging 32: 351-368, 2005.

12. Marková E, Schultz N and Belyaev IY: Kinetics and doseresponse of residual $53 \mathrm{BP} 1 / \gamma-\mathrm{H} 2 \mathrm{AX}$ foci: co-localisation, relationship with $\mathrm{DSB}$ repair and clonogenic survival. Int $\mathbf{J}$ Radiat Biol 83: 319-329, 2007.

13. Alapetite $\mathrm{C}$, Thirion $\mathrm{P}$, De la Rochefordière $\mathrm{A}$, Cosset $\mathrm{J}$ and Moustacchi E: Analyisis by alkaline comet assay of cancer patients with severe reactions to radiotherapy: defective rejoining of radioinduced DNA strand breaks in lymphocytes of breast cancer patients. Int J Cancer 83: 83-90, 1999.

14. Löbrich M, Rief N, Kühne M, Heckmann M, Fleckenstein J, Rübe $\mathrm{C}$ and Uder $\mathrm{M}$ : In vivo formation and repair of DNA double-strand breaks after computed tomography examinations. Proc Natl Acad Sci USA 102: 8984-8989, 2005.

15. Werbrouck J, De Ruyck K, Duprez F, et al: Acute normal tissue reactions in head-and neck cancer patients treated with IMRT: influence of dose and association with genetic polymorphisms in DNA DSB repair genes. Int J Radiat Oncol Biol Phys 73: 1187-1195, 2009.

16. Andreassen CN, Alsner J, Overgaard M and Overgaard J: Prediction of normal tissue radiosensitivity from polymorphisms in candidate genes. Radiother Oncol 69: 127-135, 2003.

17. Rogakou EP, Pilch DR, Orr AH, Ivanova VS and Bonner WM: DNA double stranded breaks induce histone H2AX phosphorylation on Serine 139. J Biol Chem 273: 5858-5868, 1998.

18. Rogakou EP, Boon C, Redon C and Bonner WM: Megabase chromatin domains involved in DNA double-strand breaks in vivo. J Cell Biol 146: 905-915, 1999.

19. Rothkamm K and Löbrich M: Evidence for a lack of DNA double-strand break repair in human cells exposed to very low X-ray doses. Proc Natl Acad Sci USA 100: 5057-5062, 2002.

20. Kao J, Milano MT, Javaheri A, Garofalo MC, Chmura SJ, Weichselbaum RR and Kron SJ: $\gamma-\mathrm{H} 2 \mathrm{AX}$ as a therapeutic target for improving the efficacy of radiation therapy. Curr Cancer Drug Targets 6: 197-205, 2006.

21. Bassing CH, Chua KF, Sekiguchi J, et al: Increased ionizing radiation sensitivity and genomic instability in the absence of histone H2AX. Proc Natl Acad Sci USA 99: 8173-8178, 2002.

22. Downs AJ, Lowndes NF and Jackson SP: A role for Saccharomyces cerevisiae histone HA in DNA repair. Nature 408: 1001-1004, 2000.

23. Olive PL and Banáth $\mathrm{J}$ : Phosphorylation of histone $\mathrm{H} 2 \mathrm{AX}$ as a measure of radiosensitivity. Int J Radiat Oncol Biol Phys 58: 331-335, 2004

24. Available at: http://www.hgvs.org/mutnomen. Accessed February 9, 2007.

25. Kato TA, Nagasawa H, Weil MM, Little JB and Bedford JS: Levels of $\gamma$-H2AX foci after low-dose-rate irradiation reveal a DNA DSB rejoining defect in cells from human ATM heterozygotes in two AT families and in another apparently normal individual. Radiat Res 166: 443-453, 2006.

26. Johansen J, Bentzen SM, Overgaard J and Overgaard M: Evidence for a positive correlation between in vitro radio-sensitivity of normal human skin fibroblasts and the occurrence of subcutaneous fibrosis after radiotherapy. Int J Radiat Biol 69: 407-412, 1994. 
27. Wang $\mathrm{W}$, Chen $\mathrm{Z}$, Li D, et al: Detecting normal cell radiosensitivity via assay of DNA damage in lymphocytes for individualizing radiotherapy in head and neck cancer patients. Oncology 69: 208-213, 2005.

28. MacPhail SH, Banáth JP, Yu TY, Chu EHM, Lambur H and Olive PL: Expression of phosphorylated histone H2AX in cultured cell lines following exposure to X-rays. Int J Radiat Biol 79: 351-358, 2003.

29. Banáth JP, MacPhail SH and Olive PL: Radiation sensitivity, H2AX phosphorylation, and kinetics of repair of DNA strand breaks in irradiated cervical cancer cell lines. Cancer Res 64: 7144-7149, 2004.

30. Klokov D, MacPhail SM, Banáth JP, Byrne JP and Olive PL: Phosphorylated histone $\mathrm{H} 2 \mathrm{AX}$ in relation to cell survival in tumor cells and xenografts exposed to single and fractionated doses of X-rays. Radiother Oncol 80: 223-229, 2006.
31. Taneja N, Davis M, Choy JS, Beckett MA, Singh R, Kron SJ and Weichselbaum RR: Histone H2AX phosphorylation as a predictor of radiosensitivity and target for radiotherapy. J Biol Chem 279: 2273-2280, 2004.

32. Rübe CE, Grudzenski S, Kühne M, Dong X, Rief N, Löbrich M and Rübe C: DNA double strand break repair of blood lymphocytes and normal tissues analysed in a preclinical mouse model: implications for radiosensitivity testing. Clin Cancer Res 14: 6546-6555, 2008

33. Olive PL, Banáth JP and Keyes M: Residual $\gamma \mathrm{H} 2 \mathrm{AX}$ after irradiation of human lymphocytes and monocytes in vitro and its relation to late effects after prostate brachytherapy. Radiother Oncol 86: 336-346, 2008. 